\title{
Three-dimensional/four-dimensional transperineal ultrasound: clinical utility and future prospects
}

\author{
This article was published in the following Dove Press journal: \\ International Journal of Women's Health \\ 12 September 2017 \\ Number of times this article has been viewed
}

\author{
Ginevra Salsi' \\ Ilaria Cataneo' \\ Gaia Dodaro' \\ Nicola Rizzo' \\ Gianluigi Pilu' \\ Mar Sanz Gascón ${ }^{2,3}$ \\ Aly Youssef' \\ 'Department of Obstetrics and \\ Gynecology, Sant'Orsola-Malpighi \\ University Hospital, University of \\ Bologna, Bologna, Italy; ${ }^{2}$ Department \\ of Obstetrics and Gynecology, La \\ Fé University Hospital, University \\ of Valencia, ${ }^{3}$ Prenatal Diagnosis Unit, \\ Casa del Salud University Hospital, \\ Valencia, Spain
}

\begin{abstract}
During the last decade, there has been a huge advancement in the use of transperineal ultrasound (TPU) in the field of obstetrics and gynecology. Its main applications in obstetrics include the monitoring of fetal progression in labor and recently the assessment of maternal pelvic dimensions, whereas in gynecology, TPU is at present widely used for the evaluation of the female pelvic floor, opening new boundaries for the assessment of pelvic floor disorders. The association of volumetric three-dimensional techniques has largely contributed to the remarkable progress that has occurred in the use of TPU. The aim of this paper is to offer an overview of the advantages, challenges and future perspectives of the use of TPU for women's imaging.
\end{abstract}

Keywords: transperineal ultrasound, 3D ultrasound, 4D ultrasound, TPU

\section{The use of transperineal ultrasound in gynecology}

In the past few years, the use of transperineal ultrasound (TPU) in gynecology, especially for the evaluation of the female pelvic floor, has experienced remarkable progress with a huge potential for the improvement of women's health. ${ }^{1-4} \mathrm{TPU}$ provided an objective and reproducible method for the assessment of the female pelvic floor, and considerably increased our understanding of the link between childbirth and female pelvic floor dysfunction.

Whereas two-dimensional (2D) TPU can visualize and assess reliably the midline structure of the pelvic floor ${ }^{5}$ (Figure 1), the visualization of the plane of the pelvic floor muscles (levator ani muscle, LAM) is impossible without the help of three-dimensional (3D) technique. The LAM is the main support of pelvic organs, surrounding the largest hernial orifice in the female human abdomen and pelvis, which is the pelvic hiatus. ${ }^{2,6}$ Integrity and appropriate function of LAM are main keys for normal pelvic function. Since LAM lies in the axial plane, it cannot be visualized by using 2D ultrasound; therefore, 3D ultrasound, now widely available, permits reliable assessment of both the integrity and function of LAM.

\section{Evaluation of pelvic organs prolapse}

TPU for evaluation of the pelvic organs prolapse is performed with the patient in the lithotomy position, with hips flexed and abducted. A convex transducer (3-6 MHz) is placed transperineally on the midline (Figure 1). By placing the transducer on the midsagittal plane, it is possible to visualize a section of the pubic symphysis, the urethra with the bladder, vaginal walls, perineal muscles, rectum and anal canal and anorectal angle.

The descent of the urethra, bladder, cervix and rectum during Valsalva maneuver is easily documented in the midsagittal plane with reference to a landmark defined
Correspondence: Aly Youssef Department of Obstetrics and Gynecology, Sant'Orsola-Malpighi University Hospital, University of Bologna, Via Massarenti 13, 40138 Bologna, Italy $\mathrm{Tel} / \mathrm{fax}+395$ I 2144369 Email aly.youssef78@gmail.com 

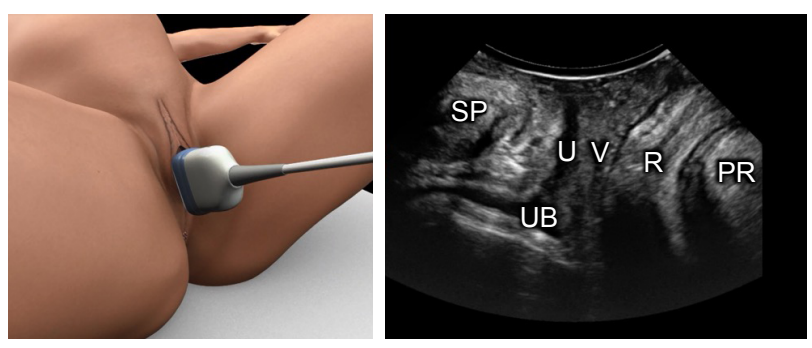

Figure I Two-dimensional view of the midsagittal plane of the pelvic floor. Note: The main structures identified on this plane are, from left to right, symphysis pubis $(\mathrm{SP})$, urethra $(\mathrm{U})$, urinary bladder $(\mathrm{UB})$, vagina $(\mathrm{V})$, rectum $(\mathrm{R})$ and the puborectalis muscle (PR) passing behind the rectum.

by the inferoposterior margin of the symphysis pubis, as described by Dietz et al. ${ }^{5}$ For this purpose, the 3D technology does not seem to add any relevant information. Nevertheless, in some cases, rendered volumes may allow complete 3D visualization of a cystocele or rectocele, and hence, 3D ultrasound is likely to become useful in the identification of fascial defects (eg, transverse or lateral tears of the rectovaginal septum) ${ }^{7}$

In addition, the acquisition of $3 \mathrm{D}$ datasets allows the storage of data for further analysis. 3D TPU may also improve intra- and interobserver reproducibility in the evaluation of pelvic organs prolapse, but further studies are needed for this purpose.

\section{Evaluation of LAM}

The real advantage of 3D TPU lies in the ability of assessing the integrity of the entire LAM in particular with its attachment to the pubic rami (also referred to as "pubovisceral muscle" or "pubococcygeus/puborectalis muscle"). ${ }^{8}$

Until a few years ago, magnetic resonance imaging (MRI) was the only imaging technique available for assessment of LAM anatomy. The advent of 3D/4D TPU now allows LAM evaluation in a more dynamic and economical way compared with MRI. While 3D TPU can reconstruct the 3D structure of LAM, the advantage of four-dimensional (4D) scan is its ability to assess the dynamic functional changes of the pelvic floor muscles under contraction and under Valsalva maneuver. It is important to point out that 2D, 3D and 4D TPU are a continuum, being complementary rather than comparable.

In 2005, Dietz et al established 3D TPU as a reliable and reproducible method for assessing LAM biometry and defined biometric parameters of LAM and levator hiatus. ${ }^{9}$ They also found a significant correlation between levator hiatus area and pelvic organ descent, thus confirming the previously set hypothesis ${ }^{8}$ of LAM anatomy and integrity playing an independent role in determining pelvic organ support.

LAM abnormalities are common in urogynecological patients, especially in parous women, and they are associated with prolapse of the anterior and central compartments. ${ }^{10}$

Although some authors measure the hiatal area using only the multiplanar mode, it has been demonstrated that thickslice reconstruction (1-2 cm using render mode) correlates more strongly with symptoms of prolapse in comparison with the sectional planes ${ }^{11}$ (Figure 2).

With 3D TPU, it is also possible to obtain "tomographic imaging", through tomographic ultrasound imaging (TUI) (Figure 3), a technique that reproduces pelvic floor "slices".

Once established that LAM defects apparently were best defined on muscular contraction, in 2007 Dietz proposed an assessment system with TUI which described the depth of the injury by counting the number of slices in which defects were identified. ${ }^{12}$ Later, the author suggested an objective measurement of LAM defects (Figure 4). The minimum distance between the center of the urethra and the insertion of the most medial component of the LAM on the pelvic sidewall on TUI images (the so-called levator-urethra gap, LUG) was found to be reproducible and strongly associated
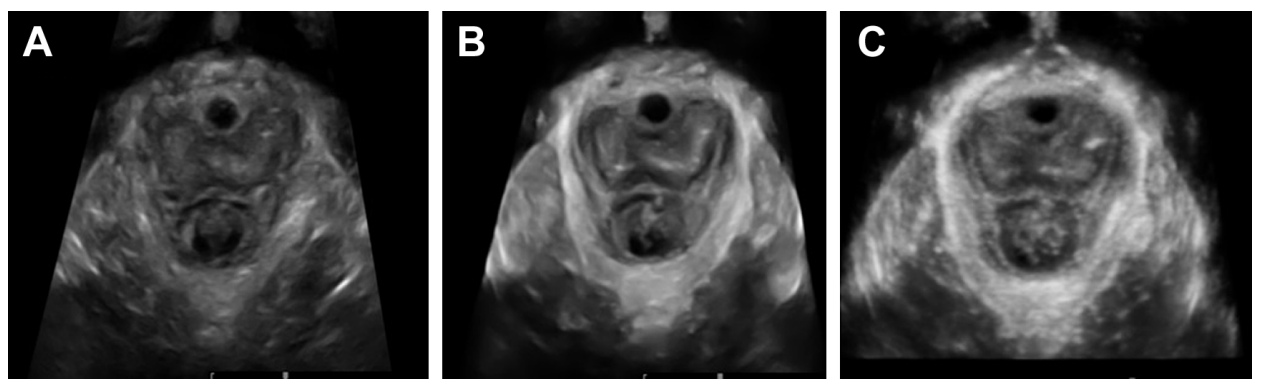

Figure 2 A comparison of the images of the axial view using the three methods for the demonstration of levator ani muscle.

Notes: Image (A) was obtained using the multiplanar mode (sectional planes) and includes a single two-dimensional slice of the three-dimensional volume. Image (B) shows the previously reported render technique and (C) shows the image obtained by the Omniview-VCl. 


\section{A}
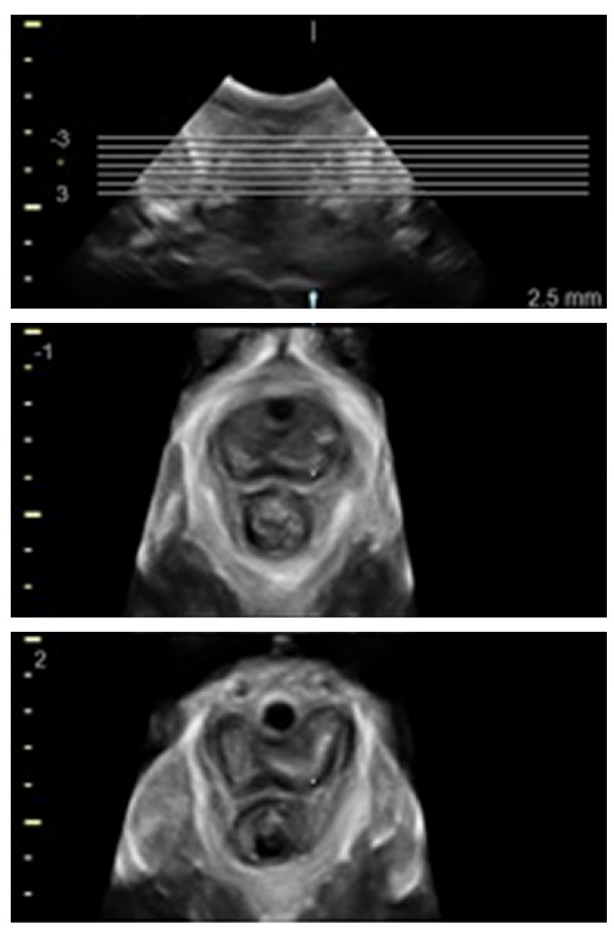

B
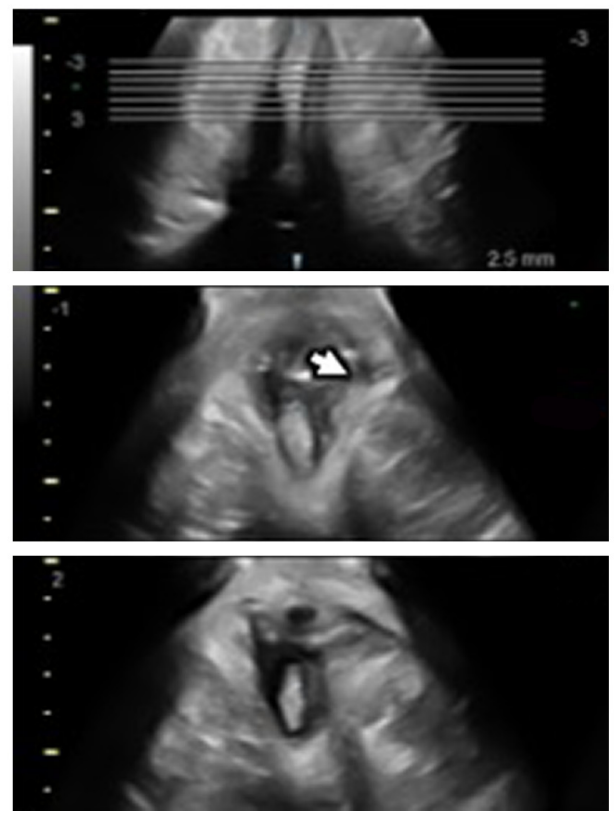
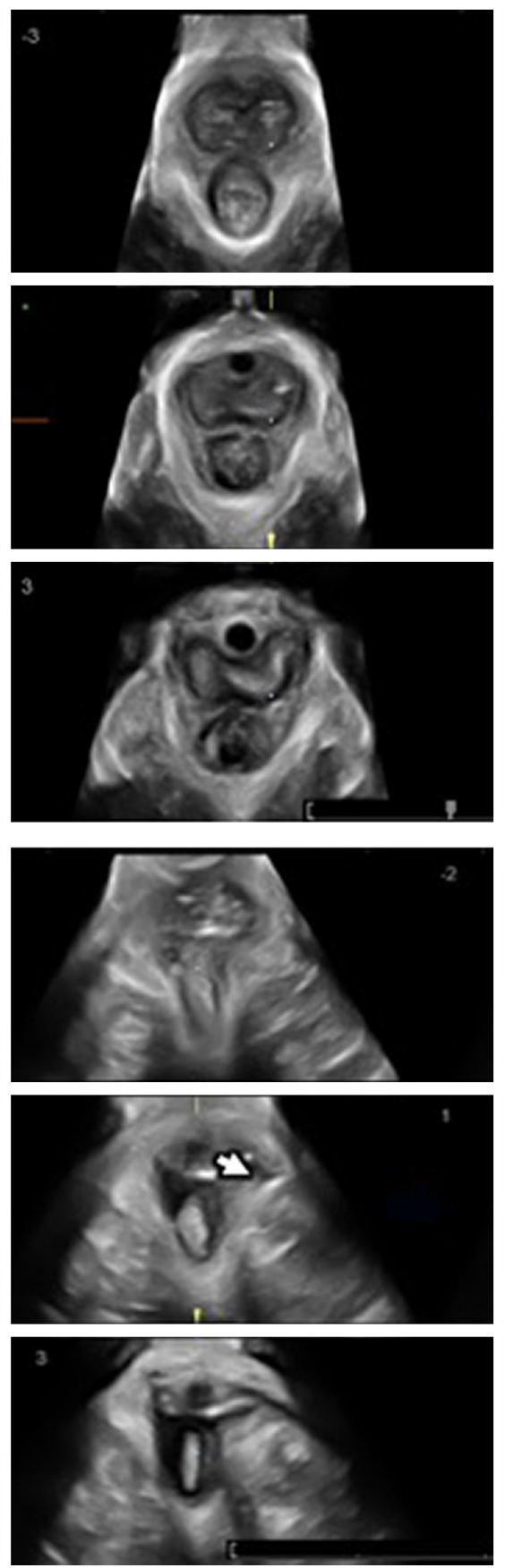
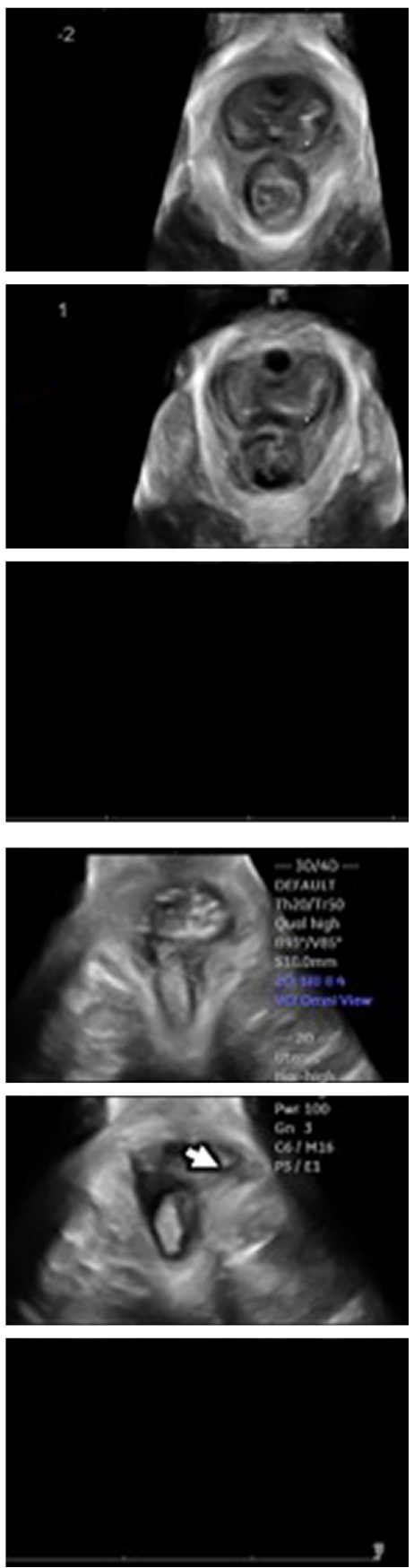

Figure 3 Tomographic ultrasound imaging of the levator ani muscle obtained by three-dimensional/four-dimensional transperineal ultrasound.

Notes: The transducer is placed in the midsagittal plane. (A) Findings are normal, with no avulsions noted. (B) An avulsion of the muscle (arrow heads) is shown.

with levator trauma detected on palpation. The author also suggested a cut-off of $25 \mathrm{~mm}$ for the diagnosis of levator avulsion injury in doubtful cases. ${ }^{13}$

\section{Pelvic floor injury diagnosed by 3D/4D TPU and pregnancy/delivery}

The association between vaginal childbirth, pelvic organ prolapse and pelvic floor dysfunction is nowadays more clearly established. ${ }^{6,14}$ It has also been demonstrated that LAM trauma and in particular a detachment or "avulsion" of the muscle from its insertion on the inferior pubic ramus and pelvic sidewall predisposes women to prolapse, especially of the anterior and central compartments. ${ }^{12}$ LAM avulsions can now be reliably diagnosed by 3D/4D TPU..$^{13,15-18}$

Levator trauma seems to be the "missing link" explaining the epidemiological association between childbirth and 

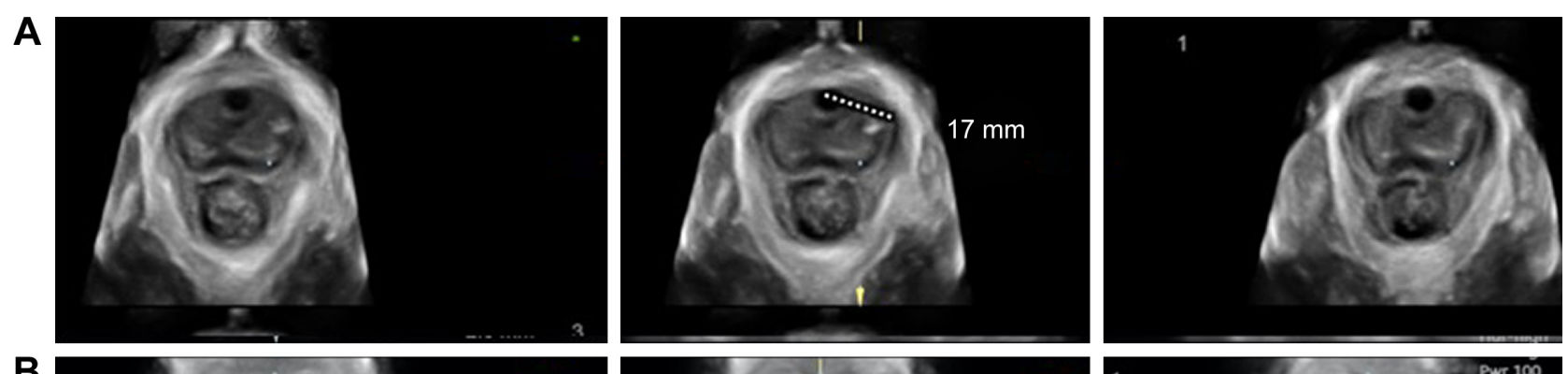

B
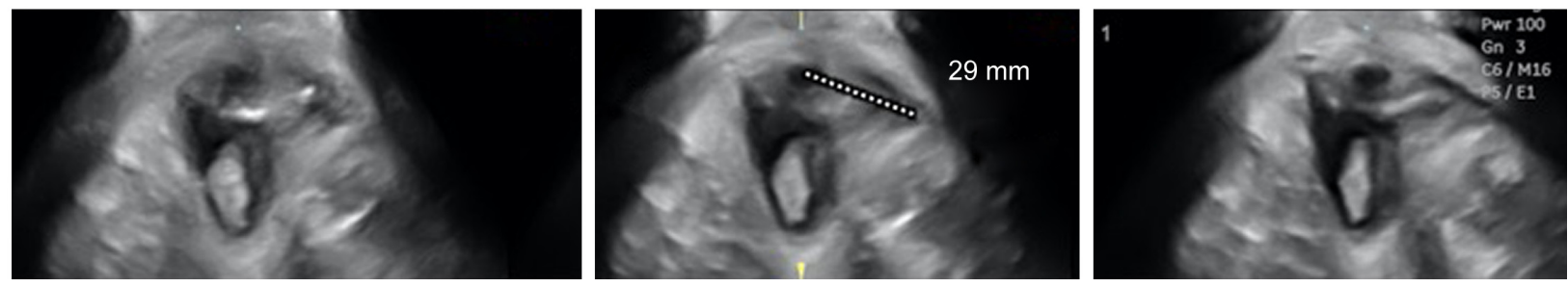

Figure 4 Measurement of the levator-urethra gap (LUG) on tomographic ultrasound imaging (TUI).

Notes: The images show the three central TUl slices used for determination of the LUG in a normal patient (the upper three images, A) and in a patient with unilateral avulsion (lower three images, B). The patient's left side is shown on the right in all images. All measurements in (A) are normal and $<25 \mathrm{~mm}$. Conversely, there is an obvious left-sided levator avulsion injury visible in (B) with measurements $>25 \mathrm{~mm}$. LUG should be measured on both sides for all three central images, but for clarity reasons in the images, only one LUG is measured on one side for each woman.

female pelvic organ prolapse. ${ }^{19}$ In fact, a 2008 study demonstrated that women examined at a urogynecological clinic presenting levator avulsion injury were approximately twice as likely to have significant pelvic organs prolapse, especially cystocele and uterine prolapse, than those with an intact levator muscle. In addition, women with significant prolapse revealed a fourfold higher prevalence of levator avulsion injury than those without. ${ }^{20}$

Whereas the vast majority of the literature on 3D/4D TPU has focused on prolapse, incontinence and the correlation between pregnancy, labor and pelvic floor dysfunction, this technique may be useful in the understanding and management of other pathologies. A very recent study by Raimondo et al, showed that women with deep infiltrating endometriosis have an increased LAM tone, and less ability to dilate their pelvic hiatus on Valsalva maneuver and to contract LAM instead of relaxing with this maneuver (LAM coactivation) ${ }^{21}$ These findings open the door for many other studies on the assessment and management of women with chronic pelvic pain disorders.

\section{Ballooning of the levator hiatus}

Further studies performed through MRI and TPU found LAM trauma in $15 \%-30 \%$ of women who delivered vaginally ${ }^{3,19}$ and concluded that LAM avulsion as a result of vaginal childbirth is associated with abnormal levator biometry and function as well as with pelvic organs prolapse. ${ }^{16,22}$

But a LAM avulsion does not seem to be the only factor involved in pelvic floor dysfunction. An enlarged hiatus can also be related to pelvic organs prolapse: in 2008, Dietz et al performed a 3D/4D TPU retrospective study with the aim of defining "normality" for hiatal area by assessing its relationship with symptoms and clinical signs of prolapse. They demonstrated that levator hiatal area is strongly associated with symptoms and clinical signs of prolapse and introduced the idea of "ballooning" (a hiatal area of $>25 \mathrm{~cm}^{2}$ on Valsalva), suggesting that this could be used as a cut-off for abnormal distensibility of the levator hiatus. ${ }^{23}$ Subsequently, vaginal delivery has been associated both with levator trauma and with hiatal enlargement. ${ }^{3}$

Using 3D/4D TPU, many authors tried to unveil the main risk factors for LAM injury.

Associations have been found with vaginal delivery, operative delivery (particularly forceps delivery, the association is uncertain for vacuum delivery) and a prolonged second stage of labor. ${ }^{22,24-27}$

Epidural analgesia may exert a protective effect, but further studies are needed to confirm this finding. ${ }^{24}$ Some authors found an association of levator injury with birthweight, but other authors ruled out this relationship. ${ }^{28}$

\section{Feasibility and repeatability of 3D/4D TPU}

As far as repeatability is concerned, a number of studies have reported data on interobserver reliability, demonstrating moderate-to-almost perfect reproducibility for measuring levator hiatal dimensions with 3D/4D TPU, both at rest and in dynamic conditions..$^{29-31}$

In accordance with these findings, van Veelen et $\mathrm{al}^{32}$ have shown that, in nulliparous and primiparous women, the 
measurement of the levator hiatus and levator-urethra gap (LUG) using 3D/4D ultrasound imaging is highly reliable. They demonstrated that the technique used to measure levator hiatal distances requires limited teaching, while LUG measurement using TUI is more challenging. ${ }^{9,29-35}$

Recently, van Delft et al have compared 3D and 4D TPU to endovaginal ultrasound and digital palpation in the evaluation of pelvic floor muscle contractility, revealing a good correlation between these three methods. ${ }^{36,37}$ In addition, they demonstrated that TPU had the further advantage of providing good visual biofeedback when training patients in pelvic floor muscle exercises.

\section{Volume contrast imaging $(\mathrm{VCl})$}

In the vast majority of the studies about 3D TPU, pelvic hiatal area is measured with multiplanar mode, which means using orthogonal 2D slices of a 3D volume. ${ }^{9}$ However, it has been shown that using a 3D/4D render of a slice measuring 1-2 cm offers more valid measurements that correlate better with the symptoms of pelvic organ prolapse. ${ }^{38}$ Nevertheless, the render technique might be more difficult than the multiplanar mode. Youssef et al recently demonstrated that a simplified technique combining linear 3D/4D reconstruction (Omniview; GE Medical Systems, Zipf, Austria) combined with contrast-enhancing tool (VCI; GE Medical Systems) could be used as a simple tool for the evaluation of the pelvic hiatal area with excellent intra- and interobserver repeatability. Furthermore, the suggested technique showed very good correlation with the $3 \mathrm{D}$ render technique ${ }^{39}$ (Figure 2). This was also confirmed during contraction and on Valsalva maneuver. They concluded that both rendering mode and OmniviewVCI can be used interchangeably for assessing pelvic hiatal area with 3D and 4D TPU. ${ }^{40}$

Very recently, the same group has demonstrated that although there is good evidence to support that the plane of the LAM is curved (warped), the degree of warping is never greater than the usual thickness of $1-2 \mathrm{~cm}$, used for the $3 \mathrm{D}$ reconstruction with the render ${ }^{6}$ and the OmniviewVCI. ${ }^{39,40}$ They confirmed that there is no need to use a curved reconstruction 3D/4D technique for the assessment of LAM. ${ }^{41}$

\section{D imaging of synthetic implant materials}

3D TPU may also be helpful in the assessment of synthetic pelvic implant materials. Most of the modern synthetic implant materials, such as tension-free vaginal tape (TVT), suprapubic arc tape (SPARC) or intravaginal slingplasty
(IVS), are highly echogenic. 3D TPU allows to distinguish among these techniques and to diagnose variations in their placement. Through 3D TPU, it is also possible to identify on the axial plane most of the injectables used in anti-incontinence surgery and placed around the urethra. ${ }^{7}$

A prospective randomized controlled trial assessed the effectiveness of suburethral slings and found that the three main types of suburethral sling (TVT, SPARC and IVS), investigated using 2D and 3D TPU, can be visualized by ultrasound and showed comparable outcomes. ${ }^{42}$

\section{Assessment of anal sphincter integrity}

Fecal incontinence occurs in approximately $2 \%$ of the adult population, and obstetric injury of the anal sphincter(OASIS) is its most common cause. ${ }^{43}$ A prompt and precise diagnosis of OASIS immediately after delivery is essential to correctly repair the anal sphincter and thus reduce the risk of fecal incontinence. Endoanal ultrasound remains the gold standard for anal sphincter assessment. MRI is a reliable technique for the evaluation of the anal sphincter complex but is expensive and not easily accessible.

With a particular attention to the obstetric context, Valsky et al, in a study on 139 patients, confirmed that 3D TPU with the multiplanar technique is an accessible and promising method for postpartum sphincter evaluation ${ }^{44}$ (Figure 5). The same group found that two-thirds of women, after third- or fourth-degree tears, suffered from some degree of incontinence and that normal later sonographic appearance of the anal sphincter complex was associated with an increased rate of clinical symptoms of incontinence. Since they found that the early sonographic signs of anal sphincter tears disappeared in almost half of the patients, they suggested that this examination should be postponed from the early postpartum period. ${ }^{45}$

Faltin et al and Guzmán Rojas et al identified significant defects of the external anal sphincter (EAS) on 3D/4D TPU with TUI technique in $27.9 \%$ of the patients who delivered vaginally. Most women with EAS damage on ultrasound $(87.0 \%)$ had not been diagnosed as having EAS tears in the delivery suite. ${ }^{46,47}$

Recently, Guzmán Rojas et al attempted to define normal residual anal sphincter defect at TUI. They suggested that four to six EAS slices showing a defect of $\geq 30^{\circ}$ should be required for the diagnosis of significant EAS trauma. ${ }^{48}$

Therefore, although endoanal ultrasound remains the gold standard for anal sphincter evaluation, there is growing evidence that 3D/4D TPU may be a valid, reliable and less invasive alternative. 

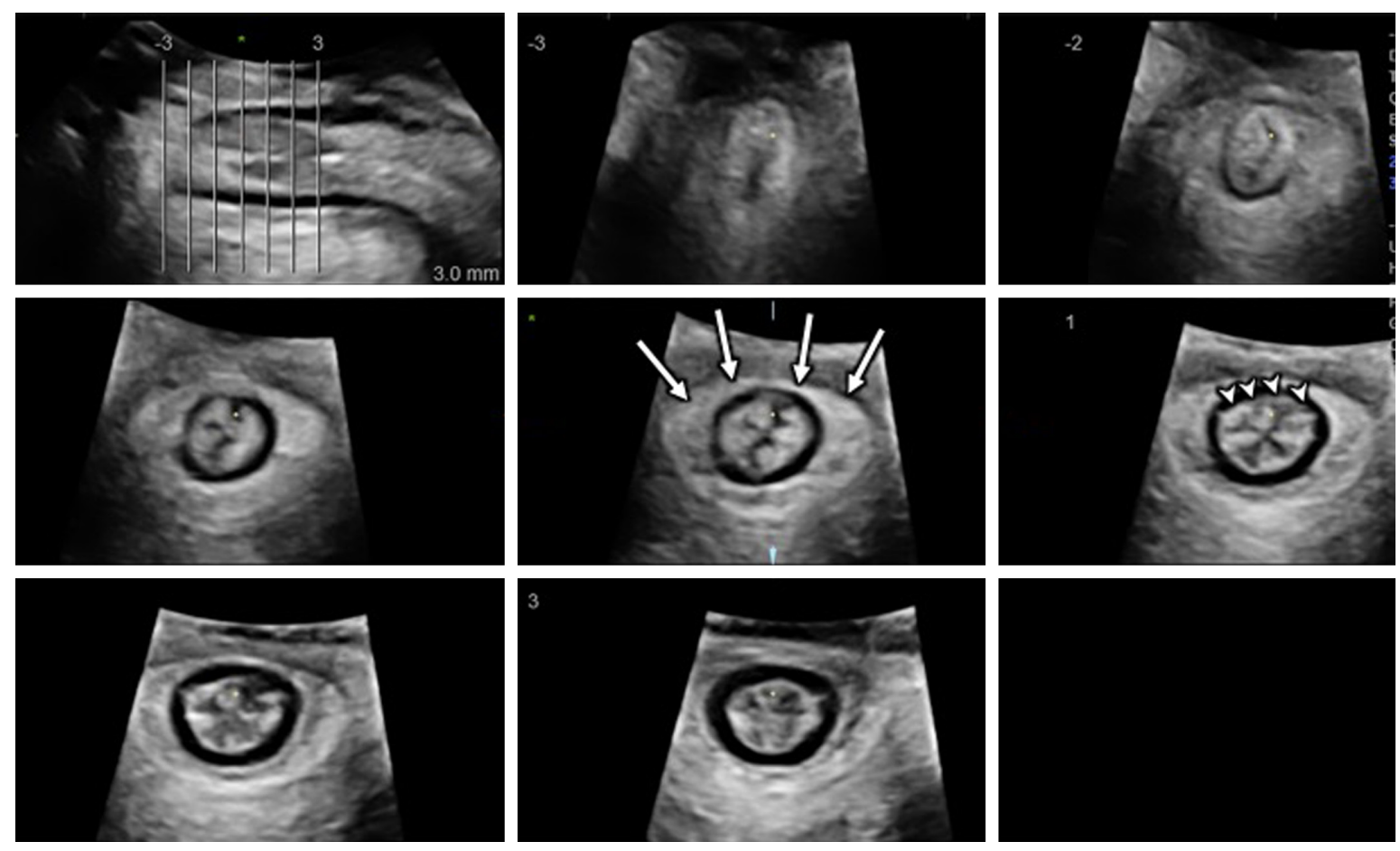

Figure 5 Three-dimensional transperineal tomographic ultrasound images of anal sphincter.

Note: Normal external (anechogenic, indicated by the arrows) and internal (hyperechogenic, indicated by the arrow heads) anal sphincters are shown.

\section{D/4D TPU in gynecology: challenges and future perspectives}

$3 \mathrm{D} / 4 \mathrm{D}$ TPU is a very rapidly evolving field, with a huge potential for the improvement of women's health, increasing our understanding of the etiology and pathophysiology of female pelvic floor dysfunction. A more widespread use of the technique, with more data on the natural history and risk factors for LAM injuries, is needed in order to plan proper prevention and rehabilitation programs for target women. Furthermore, extending pelvic floor assessment to other disorders with possible pelvic floor involvement (eg, chronic pelvic pain disorders ${ }^{21}$ may help many women to improve their lifestyles and symptoms.

\section{Obstetrics}

\section{Introduction}

To date, clinical examination remains the cornerstone of obstetrical management. Various studies demonstrated that digital assessment during the various phases of the labor has proved to be inaccurate, poorly reproducible and related to a great experience of the operator. The use of transabdominal ultrasound and TPU has been proven to be useful in many cases, as a complementary tool to clinical examination. ${ }^{49-58}$ The integration between obstetrical examination and intrapartum ultrasound could lead to an improvement in the clinical management of the patient, particularly for the choice of operative delivery during labor.

\section{TPU for the assessment of fetal occiput position}

There is a growing body of evidence to demonstrate the superiority of ultrasound in comparison to digital examination for the assessment of fetal head position. ${ }^{59-61}$ The vast majority of the published literature used the transabdominal scan. The use of TPU for the evaluation of the fetal occiput has been recently assessed with very promising results. ${ }^{52}$ However, considering the relative simplicity of the transabdominal approach, ${ }^{49}$ the latter remains from our point of view the preferred technique for fetal occiput position determination. Transabdominal ultrasound for this aim is traditionally 2D, although 3D suprapubic ultrasound can be helpful in diagnosing some fetal malpositions. ${ }^{62,63}$ Nonetheless, there is no evidence to suggest that routine use of ultrasound in labor for fetal position depiction improves outcome; therefore, this should be reserved to specific clinical conditions such as before instrumental delivery and in prolonged labor.

\section{TPU during labor for fetal head progression assessment}

TPU offers objective and reproducible measurements of various indices of fetal head progression. The acquisition of 

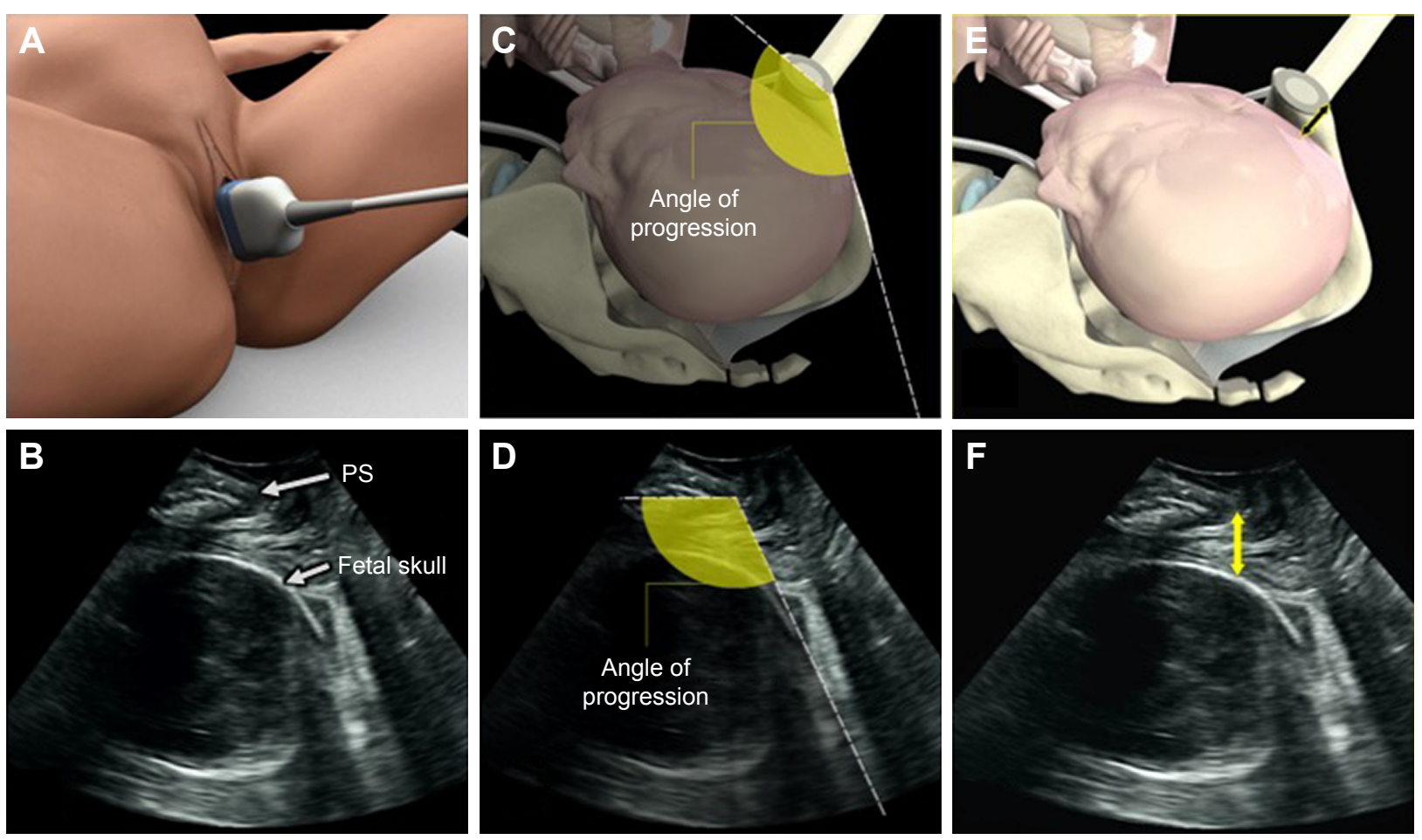

Figure 6 Technique for transperineal ultrasound scan for fetal head descent assessment on the midsagittal plane.

Notes: The convex transducer, covered by a sterile glove, is positioned translabially on the median plane (A and B) demonstrating the pubic symphysis (PS) and the fetal skull (B). On this plane, the angle of progression (C and $\mathbf{D})$ can be measured as the angle between two lines: the first one running along the long axis of the PS and the second one extending from the most inferior portion of the PS tangentially to the fetal skull contour. The fetal head-symphysis distance (E and $\mathbf{F}$ ) is the distance between the lowest edge of the pubic symphysis and the nearest point of the fetal skull along a line passing perpendicular to the long axis of PS and tangential to its lower border (reproduced from Youssef et al with permission). ${ }^{67,87}$

ultrasound images for this aim is performed with the patient in lithotomy position, using a convex transducer (volumetric in case of 3D), covered by a sterile glove. The useful planes needed for such assessments are mainly two:

1. The midsagittal plane (Figure 6): In this plane, the anatomic landmarks are the pubic symphysis displayed as oval and echogenic and the fetal head bordered by the echoic bones of the skull. Using these two bony landmarks, many TPU parameters have been suggested. ${ }^{54-56,64-67}$ These parameters assess the relationship between the two landmarks.

The introduction of the use of TPU in labor has been partially hindered by the complexity of some of the suggested parameters and by the lack of substantial evidence about their usefulness. ${ }^{68}$ For this reason, we chose in this review to present the most studied and simplest parameters from our point of view. ${ }^{69}$

Indices for labor progression measurable in the midsagittal view include:

a) The angle of progression (AoP), also called the angle of fetal head descent ${ }^{57,58,65}$ (Figure 6): This is the angle formed by a line passing through the long axis of the pubic symphysis and another line running from the lowermost part of the pubic symphysis tangential to the lowermost part of the fetal skull.

b) The head-symphysis distance (HSD) (Figure 6): This is the distance between the lowermost part of the pubic symphysis and the fetal skull on a line running perpendicular to the long axis of the pubic symphysis. ${ }^{51,67,70}$

2. The axial plane (Figure 7): This plane can be obtained by rotating the transducer $90^{\circ}$ from the midsagittal plane. TPU indices which are measurable on this plane include:

a) The head-perineum distance (HPD): This is the distance between the fetal skull and the perineum.

b) The midline angle (MLA): This is the only TPU index on the fetal head rotation. It is measured between the midline falx of the fetal brain and the anteroposterior axis of the maternal pelvis.

\section{Evidence on the use of the suggested parameters from 2D ultrasound}

AoP is one of the most studied TPU parameters. It is highly reproducible both on $2 \mathrm{D}$ and $3 \mathrm{D}$ techniques. ${ }^{71,72}$ An AoP $>120^{\circ}$ in the second stage of labor seems to be a 

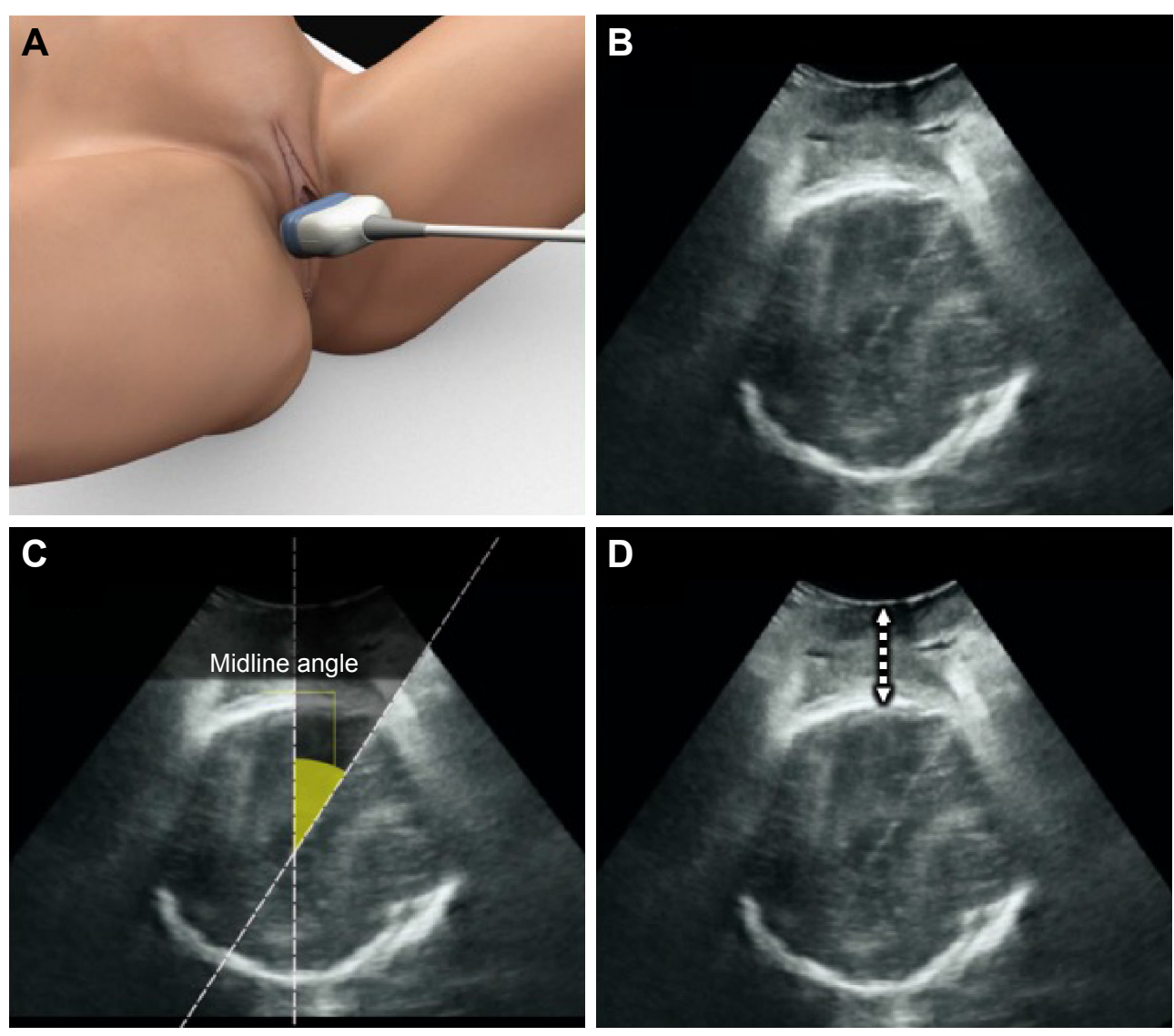

Figure 7 Technique for transperineal ultrasound scan for fetal head descent and rotation assessment on the axial plane.

Notes: The convex transducer, covered by a sterile glove, is positioned translabially on axial plane (A and $\mathbf{B})$. On this plane, the midline angle (C) and the head-perineum distance (D) can be measured (reproduced from Youssef et al with permission). ${ }^{69}$

good predictor of vaginal delivery, ${ }^{65}$ although there is no consensus on this cut-off. A positive correlation between the AoP measured during the second stage of labor and the time that elapses from the delivery has also been demonstrated. ${ }^{73}$

The HSD, described by Youssef et al in 2013, and simple to measure, has a good reproducibility and a negative correlation with the AoP. ${ }^{67,70}$ The HSD measured during the second stage of labor has also been proved to be correlated with the modality of delivery. ${ }^{51}$

The HPD, defined by Eggebø et al, decreases during the progression of the fetal head in the birth canal and correlates with the mode of delivery in the protracted labor. ${ }^{55,74}$

The MLA has the advantage of assessing the internal rotation of the fetal head. The narrower the MLA is, the lower the fetal head station is. ${ }^{64}$

Another ambitious goal for TPU is the prediction of the mode of delivery before the onset of labor. A recent study by Gillor et $\mathrm{a}^{75}$ evaluated the AoP in nulliparous women at term of pregnancy before the pharmacological induction of labor. They found that most women with uncomplicated vaginal delivery had a significantly wider preinduction AoP compared to those who had an emergency cesarean delivery. They also identified a cut-off at $92^{\circ}$ : In particular, only 5.2\% of women with an $\mathrm{AoP}>92^{\circ}$ had a cesarean section due to failure of induction or dystocia.

\section{D TPU in labor}

Most sonographic parameters assessed during labor have been widely studied using 2D ultrasound. However, some studies have questioned the reproducibility of these parameters owing to the difficulty to standardize the perfect midline and the angle of insonation. ${ }^{76}$

The main advantages of the introduction of 3D ultrasound for the transperineal assessment of fetal head in labor include:

1) Many 3D TPU parameters should be measured on the precise midsagittal plane. Using 3D ultrasound multiplanar mode, the operator can be sure of being on the exact midline, thus improving standardization of measurements.

2) Since on acquired $3 D$ datasets the three orthogonal planes can be displayed on the same volume, one can assess parameters which are measurable on various planes with 

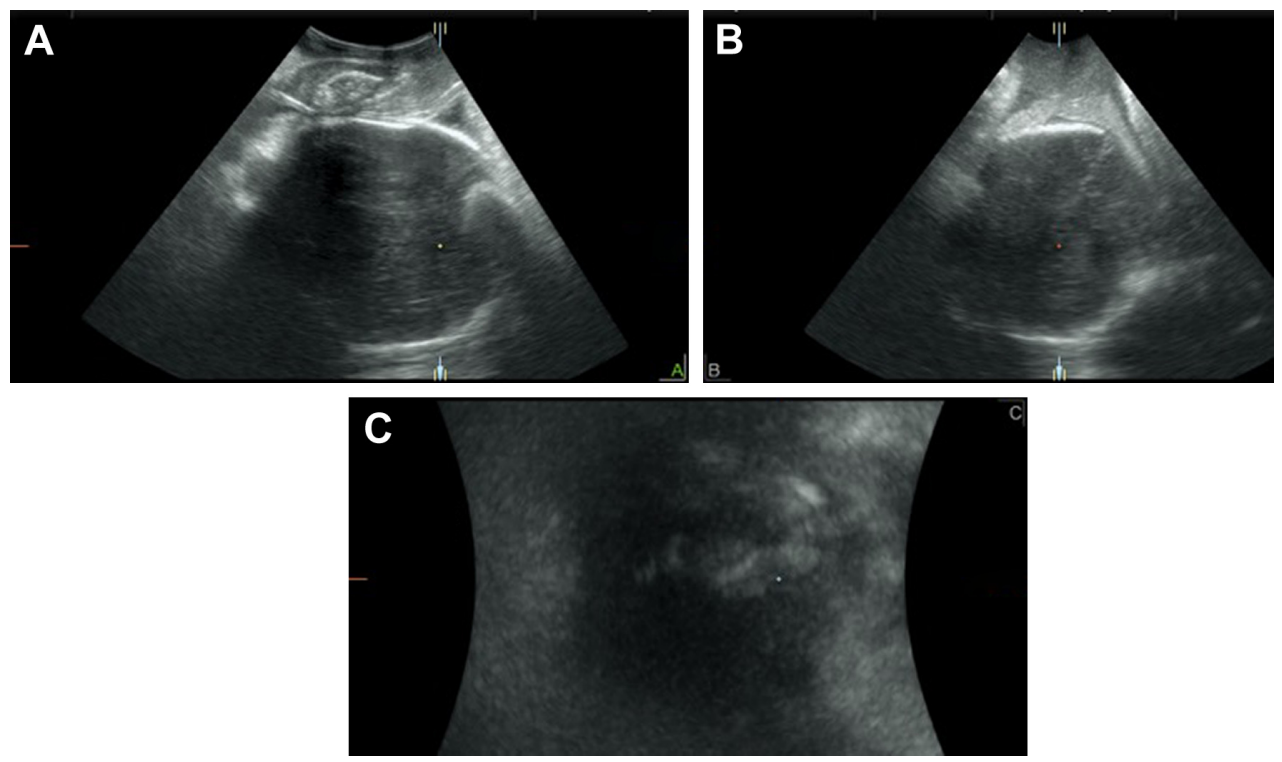

Figure 8 A multiplanar view of three-dimensional transperineal volume performed in labor.

Notes: (A) A midsagittal view of the fetal head descent below the symphysis pubis. (B) An axial view. (C) A coronal view.

only one acquisition. For example, one may be able to measure the AoP on the midsagittal plane (Figure 8) to assess the fetal head descent in relation to the pubic symphysis and the MLA on the axial plane (Figure 8) to assess fetal head rotation.

3) Post hoc analysis: 3D ultrasound volumes include a huge amount of data, which can be saved and then reanalyzed later, thus permitting many reassessments of the data.

4) Research: The saved volumes can be used later for post hoc analysis, representing an unlimited source of research.

It should be noted however that despite the abovementioned advantages, 3D/4D techniques are not indispensable for the assessment of the fetal head in labor, but it merely has the potential of providing more reproducible measurements.

\section{Technique}

The plane of acquisition is the midsagittal plane (Figure 8). A low frequency, low depth and maximum angle on 2D is set. For the 3D/4D acquisitions, a maximum angle is used. There is no need to increase the quality of 3D acquisition. Setting a medium or low quality will increase the speed of acquisition, thus saving time.

\section{Special software used in TPU}

Many studies have acquired and elaborated the ultrasound parameters in labor using a software called Sonography-based Volume Computer Aided Display labor (SonoVCAD ${ }^{\mathrm{TM}}$ labor; GE Medical Systems). One of the most important studies was carried out by the group of Molina et $\mathrm{al}^{77}$ in 2010 in a cohort of women during the second stage of labor. In this population, the authors evaluated the reproducibility of the measurements of head direction (HD), MLA, progression distance (PD) and AoP. They found some technical difficulties with the measurement of MLA especially with high head station due to inappropriate visualization of the fetal brain midline. Difficulty was also encountered with HD, as it is a dynamic subjective measurement of the direction in which the head progresses in maternal pushing, and again, it relies on visualizing the fetal intracranial structures. On the contrary, the assessment of the PD and AoP was more simple. The study demonstrated that the most reliable and reproducible parameter during labor was the AoP. The conclusions of another study, conducted by Ghi et al in 2010 on a group of nulliparous women in the second stage of labor, have led to similar results. ${ }^{71}$ Various 3D ultrasound parameters resulted highly reproducible during labor, especially AoP and PD, with less reproducibility for MLA.

Torkildsen et al in 2012 studied intraoperator reproducibility and agreement between 2D and 3D ultrasound methods in assessing AoP and HPD in cases of prolonged first stage. Both intraobserver repeatability and intermethod agreement between 2D and 3D acquisitions was satisfactory, indicating that 2D and 3D ultrasound methods might be used interchangeably. ${ }^{78}$ The association between AoP and HPD was acceptable for both 2D and 3D methods; however, the intraobserver repeatability was slightly better in $3 \mathrm{D}$ than 
2D acquisitions. Therefore, the above-mentioned studies conclude that $3 \mathrm{D}$ ultrasound is highly reproducible especially for AoP measurements, and that it may be more standardized than 2D. On the other hand, some authors advocate that in the absence of clear benefit for 3D over 2D, and in consideration of the simplicity of 2D TPU, the latter technique should be preferred in the labor room. ${ }^{78}$

Regarding the clinical applicability of 3D TPU, Ghi et al acquired datasets every 20 minutes from nulliparous women in the active second stage of labor. ${ }^{50}$ They demonstrated that a narrower AoP in the first 20 minutes and a wider MLA later in the second stage were associated with operative delivery (cesarean section or vacuum delivery). Furthermore, on logistic regression analysis, both AoP and MLA were independently associated with operative delivery. They concluded that 3D ultrasonographic assessment of fetal head descent in the second stage of labor may play a role in the prediction of the mode of delivery.

The need of a simple and reproducible parameter was demonstrated by the only survey on caregivers in the literature, which showed that about two-thirds of clinicians think that the suggested parameters were too difficult to be applied in the labor ward. ${ }^{68}$ Recently, in an attempt to reach a simple and reliable ultrasound parameter for the assessment of fetal head descent, Youssef et al suggested the measurement of the distance between the fetal head and the maternal pubic symphysis (fetal HSD). ${ }^{67}$ They demonstrated that HSD measurement with 3D TPU has excellent intra- and interobserver reproducibility and an excellent agreement with HSD measured by $2 \mathrm{D}$ ultrasound. ${ }^{49,70} \mathrm{HSD}$ also showed good correlation between 2D and 3D measurements performed by an expert operator, even in occiput posterior position of the fetal head. ${ }^{70}$ In another recent study, ${ }^{51}$ the same authors evaluated HSD during the second stage of labor at different time intervals, by analyzing 3D ultrasound datasets acquired in the context of a previous paper. ${ }^{50}$ Lower HSD values at the beginning of the second stage were associated with a higher rate of spontaneous vaginal deliveries. In particular, HSD $>24.3 \mathrm{~mm}$ in the absence of epidural analgesia and HSD $>15.7 \mathrm{~mm}$ in the presence of analgesia were associated with a higher risk of operative deliveries.

\section{The subpubic arch angle (SPA)}

Another interesting topic for the application of 3D TPU is the evaluation of maternal pelvis. The study of the maternal pelvimetry has been the subject of numerous discussions in medical literature. Digital assessment of the maternal pelvis is often imprecise and poorly reproducible. ${ }^{79} \mathrm{X}$-ray, computed tomography and MRI were often used for this aim allowing obstetricians to measure the pelvis. ${ }^{80,81}$ However, due to technical complexity and the absence of valid data confirming its usefulness, pelvimetry was not widely applied in clinical practice. Recently, ultrasound pelvimetry has been suggested. The main advantage of the use of ultrasound is its availability to the clinician, and with the introduction of 3D TPU, the pubic rami can be reliably reconstructed. ${ }^{75}$ The main limitation is the inaccessibility of ultrasound to the posterior and lateral parts of the maternal pelvis. TPU accessibility is limited to the evaluation of the anterior part of the pelvis, namely the pubic rami and the SPA. ${ }^{82-86}$ SPA is the angle formed by the two inferior branches of the pubic bone in a coronal plane. Although there is some evidence to support the use of 2D TPU for the evaluation of SPA, ${ }^{86}$ we think that the plane of the pubic arches can only be adequately evaluated by $3 \mathrm{D}$ techniques (Figure 9). ${ }^{82-85}$

It has been demonstrated that SPA assessment by 3D TPU is highly reproducible. ${ }^{82}$ Furthermore, a narrow SPA is associated with worse obstetrical outcomes, such as dystocia, vaginal operative delivery, cesarean section, prolonged labor and fetal head malpositions. ${ }^{82-85}$

Despite the strong correlation with adverse obstetrical outcome, it should be highlighted that the accuracy of SPA in the prediction of complications remains limited, ${ }^{83,84}$ and should not be used alone for clinical decision making.

\section{Challenges and future perspectives of 3D TPU in obstetrics}

As tackled above, 3D TPU is a reliable method for the assessment of fetal head progression in labor, and it is almost the only valid ultrasound technique to assess maternal pelvis. It has to be admitted however that $3 \mathrm{D}$ needs more expertise and more expensive ultrasound machines in comparison with the 2D technique. In the absence of strong evidence on its superiority, and in light of the high agreement between 2D and 3D TPU, we consider that it is reasonable to recommend the use of both techniques interchangeably in clinical practice. When the instruments and expertise are available, we think that $3 \mathrm{D}$ may offer some advantages over 2D such as higher reproducibility, adequacy for didactic purposes and the ability of post hoc analysis.

Another challenge both 2D and 3D TPU have yet to face is the need for more reliable evidence with clear cut-offs in order to help the clinicians to take decisions in labor ward. Despite the promising evidence on the matter, 

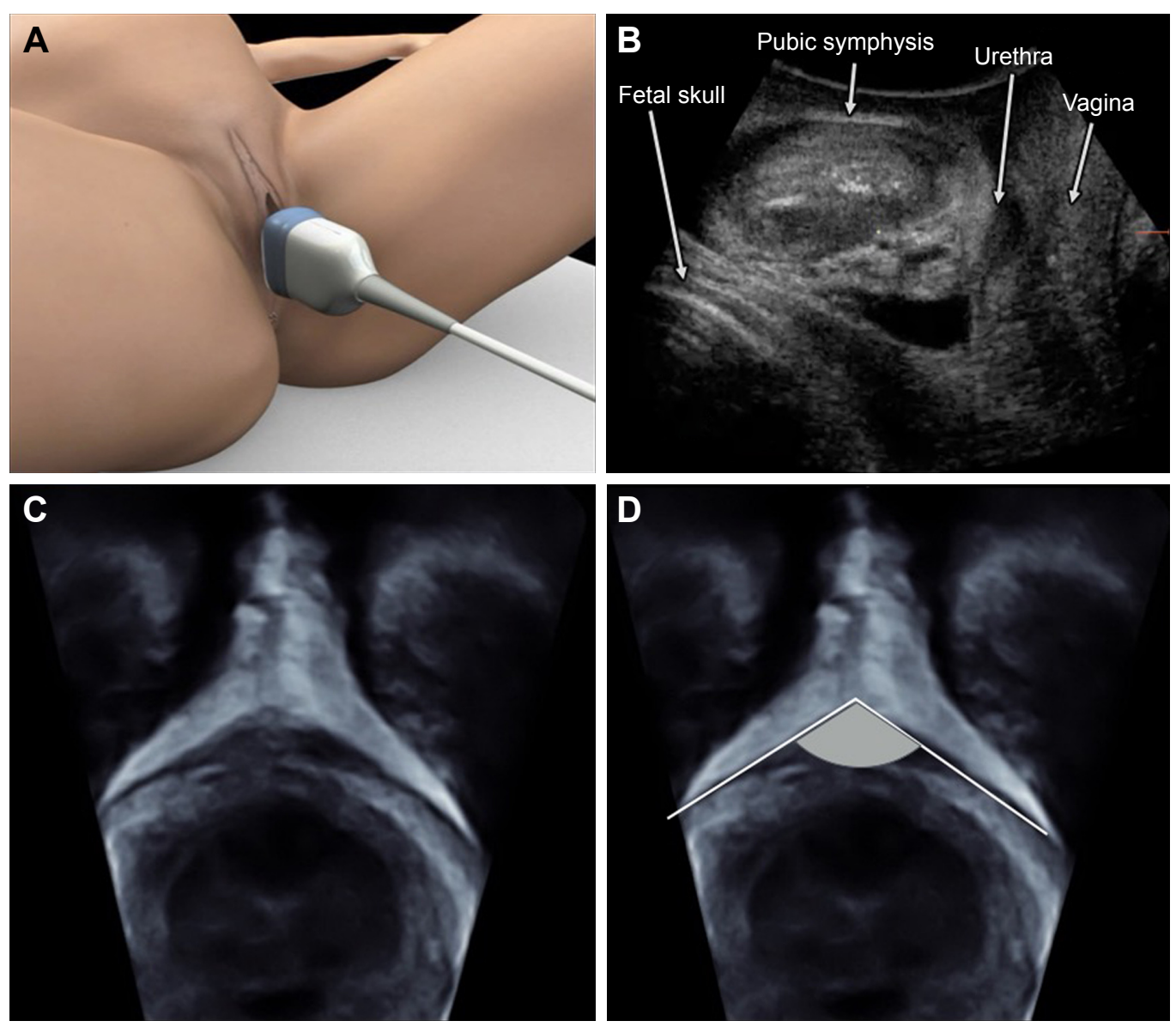

Figure 9 The subpubic arch angle (SPA).

Notes: The technique of probe positioning translabially in the median plane $(\mathbf{A})$ and the corresponding two-dimensional image (B) are shown. By drawing a line on the long axis of the pubic symphysis, it is possible to obtain a satisfactory view of the pubic rami (C). The SPA is then measured by the two-line function (D) (reproduced from Youssef et al with permission). ${ }^{84}$

data from larger populations and different centers and prospective validation are needed in order to promote a more widespread use of TPU in labor. The combination of various parameters such as indices of fetal head descent with maternal pelvic measures may significantly increase the accuracy of prediction models, although this should be thoroughly explored.

The evaluation of TPU parameters prior to the onset of labor for the prevision of labor outcomes is a very promising field that needs to be further explored as well.

\section{Conclusion}

$3 \mathrm{D} / 4 \mathrm{D}$ TPU is a very promising technique both in gynecology and in obstetrics. In gynecology, its main advantage is the evaluation of the pelvic floor muscles. For this aim, 3D/4D TPU offer a unique opportunity for diagnosing reliably pelvic floor injuries and dysfunction with a huge potential for improving women's health by detecting preventable risk factors for these lesions, by encouraging early pelvic floor rehabilitation for women with asymptomatic lesions and by providing a highly reproducible, quantitative technique for pelvic floor evaluation.

On the other hand, 3D/4D TPU provides a reliable method for fetal head rotation and descent in labor. This may help obstetricians in taking critical decisions on the basis of the reproducible measurable data, in addition to the subjective clinical assessment. Therefore, 3D/4D TPU can be used as a complementary tool in the labor ward.

\section{Disclosure}

The authors report no conflicts of interest in this work.

\section{References}

1. Dietz HP. Pelvic floor trauma following vaginal delivery. Curr Opin Obstet Gynecol. 2006;18(5):528-537.

2. DeLancey JO, Morgan DM, Fenner DE, et al. Comparison of levator ani muscle defects and function in women with and without pelvic organ prolapse. Obstet Gynecol. 2007;109(2 Pt 1):295-302.

3. Shek KL, Dietz HP. The effect of childbirth on hiatal dimensions. Obstet Gynecol. 2009;113(6):1272-1278. 
4. Dietz HP. Pelvic floor ultrasound: a review. Am J Obstet Gynecol. 2010; 202(4):321-334.

5. Dietz HP, Haylen BT, Broome J. Ultrasound in the quantification of female pelvic organ prolapse. Ultrasound Obstet Gynecol. 2001;18(5): 511-514.

6. DeLancey JO. The hidden epidemic of pelvic floor dysfunction: achievable goals for improved prevention and treatment. Am J Obstet Gynecol. 2005;192(5):1488-1495.

7. Dietz HP. Ultrasound imaging of the pelvic floor. Part II: threedimensional or volume imaging. Ultrasound Obstet Gynecol. 2004; 23(6):615-625.

8. DeLancey JO. Anatomy. In: Textbook of Female Urology and Urogynaecology, Cardozo L, Staskin D, editors. Isis Medica Media: London, UK; 2001:112-124.

9. Dietz HP, Shek C, Clarke B. Biometry of the pubovisceral muscle and levator hiatus by three-dimensional pelvic floor ultrasound. Ultrasound Obstet Gynecol. 2005;25(6):580-585.

10. Dietz HP, Steensma AB. The prevalence of major abnormalities of the levator ani in urogynaecological patients. BJOG. 2006;113(2): $225-230$.

11. Weemhoff M, Vergeldt TF, Notten K, Serroyen J, Kampschoer PH, Roumen FJ. Avulsion of puborectalis muscle and other risk factors for cystocele recurrence: a 2-year follow-up study. Int Urogynecol J. 2012;23(1):65-71.

12. Dietz HP. Quantification of major morphological abnormalities of the levator ani. Ultrasound Obstet Gynecol. 2007;29(3):329-334.

13. Dietz HP, Abbu A, Shek KL. The levator-urethra gap measurement: a more objective means of determining levator avulsion? Ultrasound Obstet Gynecol. 2008;32(7):941-945.

14. Patel DA, Xu X, Thomason AD, Ransom SB, Ivy JS, DeLancey JO. Childbirth and pelvic floor dysfunction: an epidemiologic approach to the assessment of prevention opportunities at delivery. Am J Obstet Gynecol. 2006;195(1):23-28.

15. Dietz HP, Shek C. Levator avulsion and grading of pelvic floor muscle strength. Int Urogynecol J Pelvic Floor Dysfunct. 2008;19(5): 633-636.

16. Abdool Z, Shek KL, Dietz HP. The effect of levator avulsion on hiatal dimension and function. Am J Obstet Gynecol. 2009;201(1): 89.e1-89.e5.

17. Dietz HP, Bernardo MJ, Kirby A, Shek KL. Minimal criteria for the diagnosis of avulsion of the puborectalis muscle by tomographic ultrasound. Int Urogynecol J. 2011;22(6):699-704.

18. Volloyhaug I, Wong V, Shek KL, Dietz HP. Does levator avulsion cause distension of the genital hiatus and perineal body? Int Urogynecol J. 2013;24(7):1161-1165.

19. van Delft K, Sultan AH, Thakar R, Schwertner-Tiepelmann N, Kluivers $\mathrm{K}$. The relationship between postpartum levator ani muscle avulsion and signs and symptoms of pelvic floor dysfunction. BJOG. 2014;121(9):1164-1171; discussion 1172.

20. Dietz HP, Simpson JM. Levator trauma is associated with pelvic organ prolapse. BJOG. 2008;115(8):979-984.

21. Raimondo D, Youssef A, Mabrouk M, et al. Pelvic floor muscle dysfunction at 3D/4D transperineal ultrasound in patients with deep infiltrating endometriosis: a pilot study. Ultrasound Obstet Gynecol. Epub 2016 Oct 8.

22. Durnea CM, O'Reilly BA, Khashan AS, et al. Status of the pelvic floor in young primiparous women. Ultrasound Obstet Gynecol. 2015; 46(3):356-362.

23. Dietz HP, Shek C, De Leon J, Steensma AB. Ballooning of the levator hiatus. Ultrasound Obstet Gynecol. 2008;31(6):676-680.

24. Shek KL, Dietz HP. Intrapartum risk factors for levator trauma. BJOG. 2010;117(12):1485-1492.

25. Albrich SB, Laterza RM, Skala C, Salvatore S, Koelbl H, Naumann G. Impact of mode of delivery on levator morphology: a prospective observational study with three-dimensional ultrasound early in the postpartum period. BJOG. 2012;119(1):51-60.
26. Chan SS, Cheung RY, Yiu AK, et al. Prevalence of levator ani muscle injury in Chinese women after first delivery. Ultrasound Obstet Gynecol. 2012;39(6):704-709.

27. Cassadó Garriga J, Pessarrodona Isern A, Espuña Pons M, et al. Four-dimensional sonographic evaluation of avulsion of the levator ani according to delivery mode. Ultrasound Obstet Gynecol. 2011; 38(6):701-706

28. Garcia-Mejido JA, Gutierrez-Palomino L, Borrero C, Valdivieso P, Fernandez-Palacin A, Sainz-Bueno JA. Factors that influence the development of avulsion of the levator ani muscle in eutocic deliveries: 3-4D transperineal ultrasound study. J Matern Fetal Neonatal Med. 2016; 29(19):3183-3186.

29. Yang JM, Yang SH, Huang WC. Biometry of the pubovisceral muscle and levator hiatus in nulliparous Chinese women. Ultrasound Obstetrics Gynecol. 2006;28(5):710-716.

30. Siafarikas F, Staer-Jensen J, Braekken IH, Bø K, Engh ME. Learning process for performing and analyzing $3 \mathrm{D} / 4 \mathrm{D}$ transperineal ultrasound imaging and interobserver reliability study. Ultrasound Obstet Gynecol. 2013;41(3):312-317.

31. Majida M, Braekken IH, Umek W, Bø K, Saltyte Benth J, Ellstrøm Engh M. Interobserver repeatability of three- and four-dimensional transperineal ultrasound assessment of pelvic floor muscle anatomy and function. Ultrasound Obstet Gynecol. 2009;33(5):567-573.

32. van Veelen GA, Schweitzer KJ, van der Vaart CH. Reliability of pelvic floor measurments on three- and four-dimensional ultrasound during and after first pregnancy: implications for training. Ultrasound Obstet Gynecol. 2013;42(5):590-595.

33. Braekken IH, Majida M, Ellstrøm-Engh M, Dietz HP, Umek W, Bø K. Test-retest and intra-observer repeatability of two-, three- and fourdimensional perineal ultrasound of pelvic floor muscle anatomy and function. Int Urogynecol J Pelvic Floor Dysfunct. 2008;19(2):227-235.

34. Chen R, Song Y, Jiang L, Hong X, Ye P. The assessment of voluntary pelvic floor muscle contraction by three-dimensional transperineal ultrasonography. Arch Gynecol Obstet. 2011;284(4):931-936.

35. Braekken IH, Majida M, Engh ME, Bø K. Test-retest reliability of pelvic floor muscle contraction measured by 4D ultrasound. Neurourol Urodyn. 2009;28(1):68-73.

36. van Delft K, Thakar R, Sultan AH. Pelvic floor muscle contractility: digital assessment vs transperineal ultrasound. Ultrasound Obstet Gynecol. 2015;45(2):217-222.

37. van Delft KW, Sultan AH, Thakar R, Shobeiri SA, Kluivers KB. Agreement between palpation and transperineal and endovaginal ultrasound in the diagnosis of levator ani avulsion. Int Urogynecol J. 2015; 26(1):33-39.

38. Dietz HP, Wong V, Shek KL. A simplified method for determining hiatal biometry. Aust N Z J Obstet Gynaecol. 2011;51(6):540-543.

39. Youssef A, Montaguti E, Sanlorenzo O, et al. A new simple technique for 3-dimensional sonographic assessment of the pelvic floor muscles. J Ultrasound Med. 2015;34(1):65-72.

40. Youssef A, Montaguti E, Sanlorenzo O, et al. Reliability of new threedimensional ultrasound technique for pelvic hiatal area measurement. Ultrasound Obstet Gynecol. 2016;47(5):629-635.

41. Youssef A, Cavalera M, Pacella G, et al. Is a curved 3D ultrasound reconstruction needed to assess the "warped" pelvic floor plane? Ultrasound Obstet Gynecol. Epub 2019 Sep 19.

42. Dietz HP, Barry C, Lim YN, Rane A. Two-dimensional and threedimensional ultrasound imaging of suburethral slings. Ultrasound Obstet Gynecol. 2005;26(2):175-179.

43. Huang WC, Yang SH, Yang JM. Three-dimensional transperineal sonographic characteristics of the anal sphincter complex in nulliparous women. Ultrasound Obstet Gynecol. 2007;30(2):210-220.

44. Valsky DV, Messing B, Petkova R, et al. Postpartum evaluation of the anal sphincter by transperineal three-dimensional ultrasound in primiparous women after vaginal delivery and following surgical repair of third-degree tears by the overlapping technique. Ultrasound Obstet Gynecol. 2007;29(2):195-204. 
45. Valsky DV, Cohen SM, Lipschuetz M, Hochner-Celnikier D, Yagel S. Three-dimensional transperineal ultrasound findings associated with anal incontinence after intrapartum sphincter tears in primiparous women. Ultrasound Obstet Gynecol. 2012;39(1):83-90.

46. Faltin DL, Boulvain M, Irion O, Bretones S, Stan C, Weil A. Diagnosis of anal sphincter tears by postpartum endosonography to predict fecal incontinence. Obstet Gynecol. 2000;95(5):643-647.

47. Guzmán Rojas RA, Shek KL, Langer SM, Dietz HP. Prevalence of anal sphincter injury in primiparous women. Ultrasound Obstet Gynecol. 2013;42(4):461-466.

48. Guzmán Rojas RA, Kamisan Atan I, Shek KL, Dietz HP. Anal sphincter trauma and anal incontinence in urogynecological patients. Ultrasound Obstet Gynecol. 2015;46(3):363-366.

49. Youssef A, Ghi T, Pilu G. How to perform ultrasound in labor: assessment of fetal occiput position. Ultrasound Obstet Gynecol. 2013;41(4): 476-478.

50. Ghi T, Youssef A, Maroni E, et al. Intrapartum transperineal ultrasound assessment of fetal head progression in active second stage of labor and mode of delivery. Ultrasound Obstet Gynecol. 2013;41(4):430-435.

51. Youssef A, Maroni E, Cariello L, et al. Fetal head-symphysis distance and mode of delivery in the second stage of labor. Acta Obstet Gynecol Scand. 2014;93(10):1011-1017.

52. Ghi T, Bellussi F, Eggebø T, et al. Sonographic assessment of fetal occiput position during the second stage of labor: how reliable is the transperineal approach? J Matern Fetal Neonatal Med. 2015;28(16):1985-1988.

53. Sherer DM, Miodovnik M, Bradley KS, Langer O. Intrapartum fetal head position II: comparison between transvaginal digital examination and transabdominal ultrasound assessment during the second stage of labor. Ultrasound Obstet Gynecol. 2002;19(3):264-268.

54. Dietz HP, Lanzarone V. Measuring engagement of the fetal head: validity and reproducibility of a new ultrasound technique. Ultrasound Obstet Gynecol. 2005;25(2):165-168.

55. Eggebø TM, Gjessing LK, Heien C, et al. Prediction of labor and delivery by transperineal ultrasound in pregnancies with prelabor rupture of membranes at term. Ultrasound Obstet Gynecol. 2006;27(4): 387-391.

56. Henrich W, Dudenhausen J, Fuchs I, Kämena A, Tutschek B. Intrapartum translabial ultrasound (ITU): sonographic landmarks and correlation with successful vacuum extraction. Ultrasound Obstet Gynecol. 2006;28(6):753-760.

57. Barbera AF, Pombar X, Perugino G, Lezotte DC, Hobbins JC. A new method to assess fetal head descent in labor with transperineal ultrasound. Ultrasound Obstet Gynecol. 2009;33(3):313-319.

58. Tutschek B, Braun T, Chantraine F, Henrich W. A study of progress of labour using intrapartum translabial ultrasound, assessing head station, direction, and angle of descent. BJOG. 2011;118(1):62-69.

59. Ramphul M, Ooi PV, Burke G, et al. Instrumental delivery and ultrasound: a multicentre randomised controlled trial of ultrasound assessment of the fetal head position versus standard care as an approach to prevent morbidity at instrumental delivery. BJOG. 2014;121(8):1029-1038.

60. Popowski T, Porcher R, Fort J, Javoise S, Rozenberg P. Influence of ultrasound determination of fetal head position on mode of delivery: a pragmatic randomized trial. Ultrasound Obstet Gynecol. 2015;46(5): 520-525.

61. Youssef A, Pilu G. Knowledge, understanding and fetal occiput position. Ultrasound Obstet Gynecol. 2016;47(4):523-524.

62. Ghi T, Maroni E, Youssef A, et al. Intrapartum three-dimensional ultrasonographic imaging of face presentations: report of two cases. Ultrasound Obstet Gynecol. 2012;40(1):117-118.

63. Ghi T, Youssef A, Pilu G, Malvasi A, Ragusa A. Intrapartum sonographic imaging of fetal head asynclitism. Ultrasound Obstet Gynecol. 2012;39(2):238-240.

64. Ghi T, Farina A, Pedrazzi A, Rizzo N, Pelusi G, Pilu G. Diagnosis of station and rotation of the fetal head in the second stage of labor with intrapartum translabial ultrasound. Ultrasound Obstet Gynecol. 2009; 33(3):331-336.
65. Kalache KD, Dückelmann AM, Michaelis SA, Lange J, Cichon G, Dudenhausen JW. Transperineal ultrasound imaging in prolonged second stage of labor with occipitoanterior presenting fetuses: how well does the 'angle of progression' predict the mode of delivery? Ultrasound Obstet Gynecol. 2009;33(3):326-330.

66. Tutschek B, Torkildsen EA, Eggebø TM. Comparison between ultrasound parameters and clinical examination to assess fetal head station in labor. Ultrasound Obstet Gynecol. 2013;41(4):425-429.

67. Youssef A, Maroni E, Ragusa A, et al. Fetal head-symphysis distance: a simple and reliable ultrasound index of fetal head station in labor Ultrasound Obstet Gynecol. 2013;41(4):419-424.

68. Youssef A, Ghi T, Awad EE, et al. Ultrasound in labor: a caregiver's perspective. Ultrasound Obstet Gynecol. 2013;41(4):469-470.

69. Youssef A, Bellussi F, Maroni E, Pilu G, Rizzo N, Ghi T. Ultrasound in labor: is it time for a more simplified approach? Ultrasound Obstet Gynecol. 2013;41(6):710-711.

70. Youssef A, Bellussi F, Montaguti E, et al. Agreement between two- and three-dimensional transperineal ultrasound methods for assessment of fetal head-symphysis distance in active labor. Ultrasound Obstet Gynecol. 2014;43(2):183-188.

71. Ghi T, Contro E, Farina A, Nobile M, Pilu G. Three-dimensional ultrasound in monitoring progression of labor: a reproducibility study. Ultrasound Obstet Gynecol. 2010;36(4):500-506.

72. Dückelmann AM, Bamberg C, Michaelis SA, et al. Measurement of fetal head descent using the 'angle of progression' on transperineal ultrasound imaging is reliable regardless of fetal head station or ultrasound expertise. Ultrasound Obstet Gynecol. 2010;35(2):216-222.

73. Ghi T, Maroni E, Youssef A, et al. Sonographic pattern of fetal head descent: relationship with duration of active second stage of labor and occiput position at delivery. Ultrasound Obstet Gynecol. 2014;44(1): $82-89$.

74. Eggebø TM, Hassan WA, Salvesen KA, Torkildsen EA, Østborg TB, Lees CC. Prediction of delivery mode by ultrasound-assessed fetal position in nulliparous women with prolonged first stage of labor. Ultrasound Obstet Gynecol. 2015;46(5):606-610.

75. Gillor M, Vaisbuch E, Zaks S, Barak O, Hagay Z, Levy R. Transperineal sonographic assessment of angle of progression as a predictor of a successful vaginal delivery following induction of labor. Ultrasound Obstet Gynecol. 2017;49(2):240-245.

76. Paltieli Y, Nizard J. A question of angle of view. Ultrasound Obstet Gynecol. 2009;34(3):363-364; author reply 364-366.

77. Molina FS, Terra R, Carrillo MP, Puertas A, Nicolaides KH. What is the most reliable ultrasound parameter for assessment of fetal head descent? Ultrasound Obstet Gynecol. 2010;36(4):493-499.

78. Torkildsen EA, Salvesen KÅ, Eggebø TM. Agreement between two- and three-dimensional transperineal ultrasound methods in assessing fetal head descent in the first stage of labor. Ultrasound Obstet Gynecol. 2012;39(3):310-315.

79. Böttcher B, Radley SC. Pelvimetry: changing trends and attitudes. J Obstet Gynaecol. 2001;21(5):459-462.

80. Huerta-Enochian GS, Katz VL, Fox LK, Hamlin JA, Kollath JP. Magnetic resonance-based serial pelvimetry: do maternal pelvic dimensions change during pregnancy? Am J Obstet Gynecol. 2006;194(6): 1689-1694; discussion 1694-1695.

81. Rozenberg P. [Is there a role for X-ray pelvimetry in the twenty-first century?]. Gynecol Obstet Fertil. 2007;35(1):6-12. French [with English abstract].

82. Ghi T, Youssef A, Martelli F, et al. A new method to measure the subpubic arch angle using 3-D ultrasound. Fetal Diagn Ther. 2015; 38(3):195-199.

83. Ghi T, Youssef A, Martelli F, et al. Narrow subpubic arch angle is associated with higher risk of persistent occiput posterior position at delivery. Ultrasound Obstet Gynecol. 2016;48(4):511-515.

84. Youssef A, Ghi T, Martelli F, et al. Subpubic arch angle and mode of delivery in low-risk nulliparous women. Fetal Diagn Ther. 2016;40(2): $150-155$. 
85. Youssef A, Salsi G, Cataneo I, et al. Agreement between two 3D ultrasound techniques for the assessment of the subpubic arch angle. J Matern Fetal Neonatal Med. 2016;38(3):1-5.

86. Gilboa Y, Kivilevitch Z, Spira M, et al. Pubic arch angle in prolonged second stage of labor: clinical significance. Ultrasound Obstet Gynecol. 2013;41(4):442-446.
87. Youssef A, Salsi G, Montaguti E, et al. Automated measurement of the angle of progression in labor: a feasibility and reliability study. Fetal Diagn Ther. Epub 2016 Sep 3.

International Journal of Women's Health

Dovepress

\section{Publish your work in this journal}

The International Journal of Women's Health is an international, peerreviewed open-access journal publishing original research, reports, editorials, reviews and commentaries on all aspects of women's healthcare including gynecology, obstetrics, and breast cancer. The manuscript management system is completely online and includes

a very quick and fair peer-review system, which is all easy to use. Visit http://www.dovepress.com/testimonials.php to read real quotes from published authors.

Submit your manuscript here: http://www.dovepress.com/international-journal-of-womens-health-journal 